\title{
Paradoxical Roles of the Neutrophil in Sepsis: Protective and Deleterious
}

\begin{abstract}
Fabiane Sônego ${ }^{1 \dagger}$, Fernanda Vargas e Silva Castanheira ${ }^{1}$, Raphael Gomes Ferreira ${ }^{1}$, Alexandre Kanashiro ${ }^{1}$, Caio Abner Vitorino Gonçalves Leite ${ }^{1}$, Daniele Carvalho Nascimento ${ }^{1}$, David Fernando Colón ${ }^{2}$, Vanessa de Fátima Borges ${ }^{1}$, José Carlos Alves-Filho ${ }^{1}$ and Fernando Queiróz Cunha ${ }^{1 *}$
\end{abstract}

\begin{abstract}
'Departamento de Farmacologia, Faculdade de Medicina de Ribeirão Preto, Universidade de São Paulo, Ribeirão Preto, Brazil, ${ }^{2}$ Departamento de Bioquímica e Imunologia, Faculdade de Medicina de Ribeirão Preto, Universidade de São Paulo, Ribeirão Preto, Brazil
\end{abstract}

Sepsis, an overwhelming inflammatory response syndrome secondary to infection, is one of the costliest and deadliest medical conditions worldwide. Neutrophils are classically considered to be essential players in the host defense against invading pathogens. However, several investigations have shown that impairment of neutrophil migration to the site of infection, also referred to as neutrophil paralysis, occurs during severe sepsis, resulting in an inability of the host to contain and eliminate the infection. On the other hand, the neutrophil antibacterial arsenal contributes to tissue damage and the development of organ dysfunction during sepsis. In this review, we provide an overview of the main events in which neutrophils play a beneficial or deleterious role in the outcome of sepsis.

Keywords: sepsis, neutrophil migration, organ dysfunction, toll-like receptors, chemotactic receptors

\section{INTRODUCTION}

Sepsis represents a challenging health care and economical problem worldwide with lingering aftereffects (1). The incidence of sepsis has increased over the last decades (2). In terms of diagnosis, sepsis is a systemic response to infection, with increasing severity recognized as severe sepsis or septic shock. Severe sepsis is defined as sepsis in the presence of organ dysfunction and septic shock as the presence of hypotension unresponsive to vasoconstrictors (3). Intensive preclinical studies performed in the last decades have contributed greatly to the understanding the pathophysiology of sepsis, though it is not yet fully understood. Neutrophils are important players in the outcome of sepsis. Therefore, we will review the involvement of neutrophils in the pathophysiology of sepsis in this work.

\section{CONTROL OF INFECTIONS BY NEUTROPHILS}

Neutrophils are leukocytes with multi-lobed nuclei that form in the bone marrow and are released in their mature form to the blood. Neutrophils have a short life span and do not show proliferative properties $(4,5)$.

Classically recognized as phagocytic cells, neutrophils are associated with the innate immune response. These cells are recruited to the site of the infection in response to chemotactic mediators, where they play antimicrobial roles $(5,6)$. 
The presence of neutrophils at the site of infection has been demonstrated to be essential for controlling the bacterial and fungal burden and avoiding the systemic spread of the infection (7). Indeed, depletion of neutrophils in mice infected with Staphylococcus aureus markedly reduced the clearance of the bacteria and also survival (8). Similarly, depletion of neutrophils in mice infected with Candida albicans induced dissemination of the fungus and led to a higher mortality rate. Likewise, neutropenic patients are more susceptible to bacterial and fungal infections (9-11).

Neutrophils induce killing of pathogens via phagocytosis, degranulation, or even the release of intracellular components such as DNA, histones, and lytic proteins, which form neutrophil extracellular traps (NETs) $(12,13)$. Nitric oxide (NO), a mediator produced by the enzyme inducible nitric oxide synthase (iNOS), is one crucial mediator of the microbicidal activity of neutrophils. Deletion of $i N O S$ induces a high mortality rate due to impaired control of the infection, despite the presence of neutrophils in the locale of the infection (14).

Additionally, neutrophils are equipped with receptors that recognize pathogen-associated molecular patterns or damageassociated molecular patterns, initiating signaling cascades and leading to the production of inflammatory mediators to establish an appropriate response against the pathogen. This results in amplification of the inflammatory process, including emigration of the new waves of neutrophils to the site of infection (15).

Chemokines are a family of small cytokines that are divided into small subfamilies based on variations of a conserved cysteine motif and play an important role in neutrophil recruitment (16). Most chemokines belong to the CC and CXC chemokine subfamilies (17), which exhibit two juxtaposed cysteine residues or one amino acid between the first two cysteine residues, respectively (18). Under physiological conditions, lymphocytes, monocytes, and macrophages express CC receptors (CCR) and respond to $\mathrm{CC}$ chemokines, whereas neutrophils express $\mathrm{CXC}$ receptors (CXCR)1 (IL-8R in humans) and CXCR2 and respond to CXC chemokines (19).

\section{NEUTROPHIL MIGRATION IS IMPAIRED DURING SEVERE SEPSIS}

As mentioned above, the control of an infection depends on the efficient migration of neutrophils to the site of infection as well as appropriate microbicidal activity (20). Our group and others have demonstrated that mice subjected to severe sepsis show inadequate migration of neutrophils to the site of infection, despite the high levels of chemokines at the site. The insufficient number of neutrophils recruited to the site of infection does not control the infection locally, contributing to the systemic spread of the pathogen. As consequence, a marked systemic inflammatory response is established, which is associated with high mortality rates (21).

Among the mechanisms leading to the failure of neutrophil migration, it has been shown that CXCR2 is internalized in circulating neutrophils from mice or patients with severe sepsis (22-24). Accordingly, neutrophils isolated from septic patients show reduced migration toward chemotactic mediators ex vivo, which is associated with patient survival: survivors show higher neutrophil migration compared with non-survivors (25).

In recent years, several studies have described the mechanisms underlying CXCR2 internalization in circulating neutrophils during sepsis, resulting in failure of migration to the infectious focus (Figure 1) (24, 26-29). It has been reported that chemokine receptors belong to the $\mathrm{G}$ protein-coupled receptors (GPCRs), and their expression is precisely regulated (30). Prolonged or repeated exposure to agonists induces desensitization and

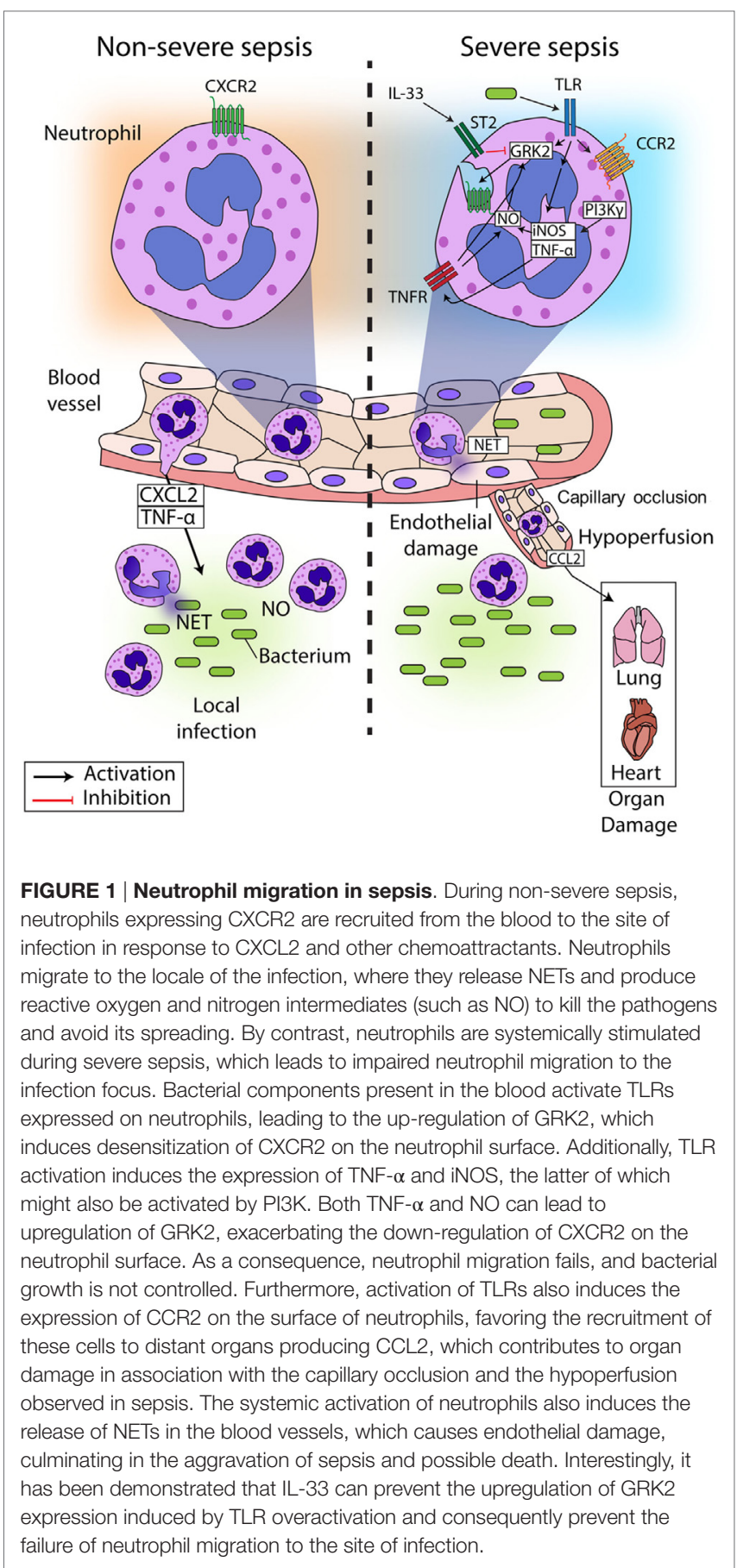


internalization of GPCRs in a process dependent on the activation of GPCR kinases (GRKs) (31). GRKs phosphorylate the intracellular domains of the activated GPCR, leading to the recruitment of arrestin, which decouples the $G$ protein from the receptor and trigger its internalization (32). Our group and others have demonstrated that ligands of Toll-like receptor (TLR)2, TLR4, and TLR9 (lipoteichoic acid (LTA), lipopolysaccharide (LPS), and CpG-oligodeoxynucleotide, respectively) induce GRK2 upregulation in circulating neutrophils, which in turn, leads to CXCR2 internalization $(26,29,33-35)$. Indeed, pretreatment of neutrophils with a GRK2 inhibitor prevented the effect of TLR4 and TLR9 activation on CXCR2 internalization $(33,34)$. Corroborating these data, tlr2-, 4-, and 9-deficient mice show an increase in CXCR2 expression on circulating neutrophils, compared with WT mice subjected to severe sepsis $(26,34,36)$. Additionally, IL-33, a member of the IL-1 family that binds to the heterodimeric receptor complex ST2, has been shown to prevent the up-regulation of GRK2 mediated by TLR signaling. IL-33 treatment improved the recruitment of neutrophils to the site of infection in mice and prevented LPS-induced chemotaxis reduction in human neutrophils $(33,37)$.

It is noteworthy that in contrast to the harmful TLR overactivation in circulating neutrophils, adequate activation of TLRs in migrated neutrophils is crucial for establishing the local immune response. Indeed, tlr4-mutant mice fail to control a low-dose infection with the Gram-negative bacterium Salmonella typhimurium (36). Moreover, myd88-deficient mice are highly susceptible to polymicrobial sepsis because the lack of the adaptor protein involved in most of TLR signaling prevents the establishment of the local inflammatory response. In contrast to the TLRs, the pattern recognition receptors Nod-like receptors 1 and 2 are not involved in neutrophil migration to the site of infection or in the establishment of the inflammatory response locale in mice subjected to CLP-induced polymicrobial sepsis (38).

Further investigation of how TLRs modulate the expression of CXCR2 on the neutrophil surface suggested the involvement of tumor necrosis factor (TNF)- $\alpha$ and NO. Neutrophils isolated from tnf receptor-deficient mice activated with LPS do not show internalization of CXCR2 or impaired chemotaxis to CXCL2. Additionally, neutrophils treated with TNF- $\alpha$ exhibit reduced chemotaxis toward CXCL2 (27). Moreover, NO confers a similar effect in LPS- or IL-8-stimulated neutrophils. Indeed, inhibition of iNOS reduces the effect of the LPS or IL- 8 on the internalization of CXCR2 and the chemotactic activity of CXCR2 agonists $(24,29)$. NO triggers the activation of soluble guanylate cyclases (GCs) as well as cyclic-GMP formation and protein kinase G (PKG) phosphorylation (39). As expected, inhibition of sGC or PKG had the same effect as iNOS inhibition after LPS stimulation of neutrophils. Interestingly, inhibition of sGC and PKG during experimental sepsis protected mice from death, and this effect was associated with reduced expression of GRK2 in neutrophils, increased expression of CXCR2 and, consequently, increased neutrophil migration to the infectious focus compared with non-treated animals (29).

Based on these observations, we could suggest that TNF- $\alpha$ production and/or release in neutrophils is important to the effect of TLRs on the CXCR2 expression on these cells. In addition, both TLR- and TNF-dependent pathways upregulate inducible NO synthase, which could in turn induce GRK2 expression, leading to reduced CXCR2 expression on the neutrophil surface (40).

In addition to TNF- $\alpha$ and iNOS, it has been demonstrated that phosphoinositide-3 kinase gamma (PI3K $\gamma$ ) plays an important role in this process (28). Interestingly, PI3K may be involved in the dimerization of iNOS, an essential process for the activity of this enzyme (41). GRK2 upregulation and CXCR2 internalization were shown to be inhibited in $\mathrm{PI} 3 \mathrm{~K}^{-/-}$neutrophils incubated with CXCL2. Additionally, $P I 3 \mathrm{~K}^{-/-}$mice subjected to CLP present reduced GRK2 expression and increased CXCR2 expression on the neutrophil surface, resulting in higher survival rates (28). Altogether, these data provide substantial evidence of the links between all pathways discussed above and highlight new potential targets for sepsis treatment.

In contrast to the deleterious role of the pathways described above, there are also mediators that protect the organism against sepsis. One example is hydrogen sulfide $\left(\mathrm{H}_{2} \mathrm{~S}\right)$, a gas produced by the organism that is synthesized from L-cysteine, mainly via the cystathionine b-synthase and cystathionine g-lyase (CSE) enzymes (42). It has been demonstrated that CSE activity is increased during sepsis, and inhibition of CSE reduces CLP-induced leukocyte-endothelial interactions in mesenteric venules, decreases neutrophil migration to the site of infectious, and consequently decreases the survival rate of animals subjected to non-severe sepsis (43). In contrast, treatment of mice subjected to severe sepsis with an $\mathrm{H}_{2} \mathrm{~S}$ donor has the opposite effect, resulting in increased CXCR2 expression on circulating neutrophils, increased neutrophil migration to the infection focus, and improvement survival (43). Thus, $\mathrm{H}_{2} \mathrm{~S}$ donors could be considered for use in sepsis treatment.

Additionally, neutrophil migration events during sepsis have been demonstrated to be regulated by several other mediators, such as lectin-like oxidized low-density lipoprotein receptor (LOX)-1, peroxynitrite, and the acute-phase alpha-1 acid protein, which contribute to the failure of neutrophil migration to the site of infection (44-46). Conversely, the cytokine IL-17 has been shown to be crucial for recruiting neutrophils to the site of infection during sepsis (47). In contrast, the role of the peroxisome proliferator-activated receptor in neutrophil migration during sepsis remains to be confirmed, as both protective and deleterious role have been described $(48,49)$. The effects of these mediators on the neutrophil migration have been reviewed elsewhere $(20,50,51)$ and will not be further addressed here.

\section{NEUTROPHIL-INDUCED ORGAN DAMAGE}

In addition to the host-protective role of neutrophils in sepsis via the killing of microorganisms, these cells have been described as exhibiting deleterious functions (6). During sepsis, it has been shown that the systemic inflammatory response leads to the activation of circulating neutrophils sequestered in capillary beds, occluding the lumen, and inducing tissue ischemia. Additionally, neutrophils can migrate to vital organs and release lytic factors and pro-inflammatory cytokines, contributing to organ damage and subsequent multiple organ dysfunction $(52,53)$. Chemokines 
and chemokine receptors are also involved in the process of neutrophil infiltration into vital organs during sepsis. In contrast to the observation that CXCR2 is internalized in circulating neutrophils during severe sepsis (24), this receptor has been implicated in neutrophil infiltration into the lungs, due to the release of CXC chemokines in this organ during sepsis $(54,55)$. This apparent contradiction could be explained by the differences in the severity of sepsis induced in each study.

Furthermore, our group and others have demonstrated that CCR receptors, which are not expressed on neutrophils under physiological conditions, are induced in this cell type in various inflammatory processes (56-60). It was demonstrated that CCR2 is induced on the neutrophil surface in mice and patients with sepsis in a TLR2- or TLR4-dependent manner. Importantly, CCR2 does not mediate neutrophil recruitment to the site of infection, but it does mediate neutrophil infiltration in vital organs, such as the lungs, kidneys, and heart. Blockage of CCR2 decreases organ damage and death in animals subjected to severe CLP. Moreover, CCR2 expression is positively correlated with the severity of the disease, as measured using the Sepsis-related Organ Failure Assessment (SOFA) score. Accordingly, human neutrophils isolated from non-surviving septic patients express more CCR2 than neutrophils from surviving patients (59).

Another important feature of neutrophils is the formation of NETs, a network of chromatin fibers associated with granules of antimicrobial peptides and enzymes such as myeloperoxidase, elastase, and cathepsin G, which immobilize and kill invading microorganisms to prevent their spreading (61). The role of NETs in the control of bacterial spreading in sepsis is controversial. Similar bacterial loads were observed in animals lacking an important enzyme (peptidylarginine deiminase 4) for NET formation and in animals treated with rhDNAse compared with control mice $(62,63)$. However, our group and others $(64,65)$ have observed an important role of NETs in the control of bacterial spreading during sepsis.

In addition to the role of the NETs in bacterial control during infection, excessive formation of NETs has been observed in many pathological conditions, which is related to organ damage (66). Activated endothelial cells induce the formation of NETs by neutrophils in vitro $(67,68)$. Moreover, in an LPS-induced endotoxic shock model, NETs have adhered and activated the vascular endothelium (69). Additionally, the interaction between neutrophils and activated platelets during sepsis induces NET formation, which contributes to endothelial cell damage and organ injuries (70). Moreover, it has been reported that histones and myeloperoxidase could be responsible for NET-induced endothelial dysfunction, and histones can also interact with TLR2 and TLR4 to induce cytokine production via MyD88 signaling, contributing to the systemic inflammatory response observed in sepsis $(68,71-74)$.

Surprisingly, the survival rate was not found to differ between rhDNAse-treated and non-treated mice after CLP (65). Further investigations revealed that this lack of a difference was due to the deleterious role of NETs in organ damage, as discussed above. Thus, when antibiotic therapy and rhDNAse treatment or inhibition of the enzyme peptidylarginine deiminase 4 were used in combination to control a bacterial infection, a marked increase in the survival rate of the animals was observed, which was associated with decreased organ damage $(63,65)$. In addition, pretreatment with rh-DNAse in animals challenged with LPS decreased the organ damage and increased the survival rate during endotoxemia (65).

The observations from mouse models confirm the human ones. Notably, autopsy examinations of tissues from septic patients with multiple organ dysfunction syndrome indicate the presence of neutrophils sequestered into the kidneys and lungs (75). Furthermore, severity of acute respiratory distress syndrome in septic patients is proportional to the intensity of the inflammatory infiltrate and proteolytic enzymes in the bronchoalveolar lavage (76).

During sepsis, organ failure is associated with hypoperfusion and tissue hypoxia, both of which are attributed to hypotension and occlusion of neutrophils in the microcirculation $(77,78)$. The cytokines secreted by neutrophils attached to a vessel wall can also cause endothelial dysfunction, establishing a thrombogenic profile and favoring intravascular coagulation (79). Additionally, neutrophil products can also induce increased NO production by various cell types, which can contribute to lowering blood pressure (80) and favors the generation of peroxynitrite, a potent oxidant agent. In the heart, peroxynitrite can cause changes in the structure and function of proteins that may be related to sepsis-associated myocardial failure (81). Thus, the adhesion of neutrophil to the endothelium and their sequestration to the heart may have multiple deleterious cardiovascular effects.

\section{CONCLUSION AND PERSPECTIVES}

It is clear that sepsis continues to represent a challenge for basic and clinical researchers. Despite the massive amount of basic and clinical results related to this syndrome that has been published in the literature in the last several decades, there has been an absence of effective new treatments. The high mortality associated with sepsis together with its increased incidence, points to the importance of re-evaluation of the literature as well as the new translational studies addressing the disease. Together, these approaches will help to identify new effective targets for the development of new therapies. In this context, the present review described the dual roles of neutrophils in the evolution of sepsis. These cells are key players in the innate immune response in the early phase of sepsis and their recruitment to sites of infection is crucial for controlling microorganism growth. Aggravation of sepsis is associated with failure of neutrophil migration to the site of infection. The molecular mechanism involved in this phenomenon was described, and several potential targets for the development of new therapies were identified. By contrast, neutrophils can be harmful and induce secondary organ damage during infection. Neutrophil recruitment to organs far from the site of infection is mediated by the expression of CCR2 under septic conditions. The mechanism involved in the harmful effect of the neutrophils was also described in this review, noting potential targets for the development of new therapies. In this context, new therapies targeting the harmful activity of neutrophils, such as blocking 
NET formation or CCR2 activity, might be more helpful than targeting the general inflammatory response.

\section{AUTHOR CONTRIBUTIONS}

FS, FC, AK, CL, RF, DN, DC, VB, JA-F, and FC wrote and approved the text. CL draws the figure.

\section{REFERENCES}

1. Horeczko T, Green JP, PanacekEA. Epidemiology of the Systemic Inflammatory Response Syndrome (SIRS) in the emergency department. West J Emerg Med (2014) 15:329-36. doi:10.5811/westjem.2013.9.18064

2. Kumar G, Kumar N, Taneja A, Kaleekal T, Tarima S, McGinley E, et al. Nationwide trends of severe sepsis in the 21st century (2000-2007). Chest (2011) 140:1223-31. doi:10.1378/chest.11-0352

3. Bone RC, Sibbald WJ, Sprung CL. The ACCP-SCCM consensus conference on sepsis and organ failure. Chest (1992) 101:1481-3. doi:10.1378/ chest.101.6.1481

4. Galli SJ, Borregaard N, Wynn TA. Phenotypic and functional plasticity of cells of innate immunity: macrophages, mast cells and neutrophils. Nat Immunol (2011) 12:1035-44. doi:10.1038/ni.2109

5. Kolaczkowska E, Kubes P. Neutrophil recruitment and function in health and inflammation. Nat Rev Immunol (2013) 13:159-75. doi:10.1038/nri3399

6. Mantovani A, Cassatella MA, Costantini C, Jaillon S. Neutrophils in the activation and regulation of innate and adaptive immunity. Nat Rev Immunol (2011) 11:519-31. doi:10.1038/nri3024

7. Ermert D, Zychlinsky A, Urban C. Fungal and bacterial killing by neutrophils. Methods Mol Biol (2009) 470:293-312. doi:10.1007/978-1-59745-204-5_21

8. Robertson CM, Perrone EE, McConnell KW, Dunne WM, Boody B, Brahmbhatt $\mathrm{T}$, et al. Neutrophil depletion causes a fatal defect in murine pulmonary Staphylococcus aureus clearance. J Surg Res (2008) 150:278-85. doi:10.1016/j.jss.2008.02.009

9. Bouma G, Ancliff PJ, Thrasher AJ, Burns SO. Recent advances in the understanding of genetic defects of neutrophil number and function. Br J Haematol (2010) 151:312-26. doi:10.1111/j.1365-2141.2010.08361.x

10. Brown GD, Denning DW, Gow NA, Levitz SM, Netea MG, White TC. Hidden killers: human fungal infections. Sci Transl Med (2012) 4:165rv113. doi:10.1126/scitranslmed.3004404

11. Swamydas M, Gao JL, Break TJ, Johnson MD, Jaeger M, Rodriguez CA, et al. CXCR1-mediated neutrophil degranulation and fungal killing promote Candida clearance and host survival. Sci Transl Med (2016) 8:322ra310. doi:10.1126/scitranslmed.aac7718

12. Nathan C. Neutrophils and immunity: challenges and opportunities. Nat Rev Immunol (2006) 6:173-82. doi:10.1038/nri1785

13. Bardoel BW, Kenny EF, Sollberger G, Zychlinsky A. The balancing act of neutrophils. Cell Host Microbe (2014) 15:526-36. doi:10.1016/j.chom.2014.04.011

14. Benjamim CF, Silva JS, Fortes ZB, Oliveira MA, Ferreira SH, Cunha FQ. Inhibition of leukocyte rolling by nitric oxide during sepsis leads to reduced migration of active microbicidal neutrophils. Infect Immun (2002) 70:3602-10. doi:10.1128/IAI.70.7.3602-3610.2002

15. Bianchi ME. DAMPs, PAMPs and alarmins: all we need to know about danger. J Leukoc Biol (2007) 81:1-5. doi:10.1189/jlb.0306164

16. Luster $\mathrm{AD}$. Chemokines - chemotactic cytokines that mediate inflammation. N Engl J Med (1998) 338:436-45. doi:10.1056/nejm199802123380706

17. Graham GJ. D6 and the atypical chemokine receptor family: novel regulators of immune and inflammatory processes. Eur J Immunol (2009) 39:342-51. doi:10.1002/eji.200838858

18. Rollins BJ. Chemokines. Blood (1997) 90:909-28.

19. Mantovani A, Bonecchi R, Locati M. Tuning inflammation and immunity by chemokine sequestration: decoys and more. Nat Rev Immunol (2006) 6:907-18. doi:10.1038/nri1964

20. Sonego F, Alves-Filho JC, Cunha FQ. Targeting neutrophils in sepsis. Expert Rev Clin Immunol (2014) 10:1019-28. doi:10.1586/1744666X.2014.922876

\section{FUNDING}

This work was supported by São Paulo Research Foundation (FAPESP), grant \#2008/11593-4 and \#2011/19670-0, CNPq (Conselho Nacional de Desenvolvimento Científico e Tecnológico) and European Community's Seventh Framework Programme [FP7-2007-2013] under grant agreement $\mathrm{n}^{\circ}$ HEALTH-F4-2011-281608 (TIMER).

21. Alves-Filho JC, de Freitas A, Spiller F, Souto FO, Cunha FQ. The role of neutrophils in severe sepsis. Shock (2008) 30(Suppl 1):3-9. doi:10.1097/ SHK.0b013e3181818466

22. Chishti AD, Shenton BK, Kirby JA, Baudouin SV. Neutrophil chemotaxis and receptor expression in clinical septic shock. Intensive Care Med (2004) 30:605-11. doi:10.1007/s00134-004-2175-y

23. Arraes SM, Freitas MS, da Silva SV, de Paula Neto HA, Alves-Filho JC, Auxiliadora Martins M, et al. Impaired neutrophil chemotaxis in sepsis associates with GRK expression and inhibition of actin assembly and tyrosine phosphorylation. Blood (2006) 108:2906-13. doi:10.1182/blood-2006-05-024638

24. Rios-Santos F, Alves-Filho JC, Souto FO, Spiller F, Freitas A, Lotufo CM, et al. Down-regulation of CXCR2 on neutrophils in severe sepsis is mediated by inducible nitric oxide synthase-derived nitric oxide. Am J Respir Crit Care Med (2007) 175:490-7. doi:10.1164/rccm.200601-103OC

25. Tavares-Murta BM, Zaparoli M, Ferreira RB, Silva-Vergara ML, Oliveira $\mathrm{CH}$, Murta EF, et al. Failure of neutrophil chemotactic function in septic patients. Crit Care Med (2002) 30:1056-61. doi:10.1097/ 00003246-200205000-00017

26. Alves-Filho JC, Freitas A, Souto FO, Spiller F, Paula-Neto H, Silva JS, et al. Regulation of chemokine receptor by Toll-like receptor 2 is critical to neutrophil migration and resistance to polymicrobial sepsis. Proc Natl Acad Sci U S A (2009) 106:4018-23. doi:10.1073/pnas.0900196106

27. Secher T, Vasseur V, Poisson DM, Mitchell JA, Cunha FQ, Alves-Filho JC, et al. Crucial role of TNF receptors 1 and 2 in the control of polymicrobial sepsis. J Immunol (2009) 182:7855-64. doi:10.4049/jimmunol.0804008

28. Martin EL, Souza DG, Fagundes CT, Amaral FA, Assenzio B, Puntorieri V, et al. Phosphoinositide-3 kinase gamma activity contributes to sepsis and organ damage by altering neutrophil recruitment. Am J Respir Crit Care Med (2010) 182:762-73. doi:10.1164/rccm.201001-0088OC

29. Paula-Neto HA, Alves-Filho JC, Souto FO, Spiller F, Amendola RS, Freitas A, et al. Inhibition of guanylyl cyclase restores neutrophil migration and maintains bactericidal activity increasing survival in sepsis. Shock (2011) 35:17-27. doi:10.1097/SHK.0b013e3181e37ea8

30. Murdoch C, Finn A. Chemokine receptors and their role in inflammation and infectious diseases. Blood (2000) 95:3032-43.

31. Moore CA, Milano SK, Benovic JL. Regulation of receptor trafficking by GRKs and arrestins. Annu Rev Physiol (2007) 69:451-82. doi:10.1146/annurev. physiol.69.022405.154712

32. Lefkowitz RJ, Shenoy SK. Transduction of receptor signals by beta-arrestins. Science (2005) 308:512-7. doi:10.1126/science.1109237

33. Alves-Filho JC, Sonego F, Souto FO, Freitas A, Verri WA Jr, AuxiliadoraMartins M, et al. Interleukin-33 attenuates sepsis by enhancing neutrophil influx to the site of infection. Nat Med (2010) 16:708-12. doi:10.1038/nm.2156

34. Trevelin SC, Alves-Filho JC, Sonego F, Turato W, Nascimento DC, Souto FO, et al. Toll-like receptor 9 activation in neutrophils impairs chemotaxis and reduces sepsis outcome. Crit Care Med (2012) 40:2631-7. doi:10.1097/ CCM.0b013e318258fb70

35. Lee SK, Kim SD, Kook M, Lee HY, Ghim J, Choi Y, et al. Phospholipase D2 drives mortality in sepsis by inhibiting neutrophil extracellular trap formation and down-regulating CXCR2. J Exp Med (2015) 212:1381-90. doi:10.1084/ jem.20141813

36. Alves-Filho JC, de Freitas A, Russo M, Cunha FQ. Toll-like receptor 4 signaling leads to neutrophil migration impairment in polymicrobial sepsis ${ }^{*}$. Crit Care Med (2006) 34:461-70. doi:10.1097/01.ccm.0000198527.71819.e1

37. Le HT, Tran VG, Kim W, Kim J, Cho HR, Kwon B. IL-33 priming regulates multiple steps of the neutrophil-mediated anti-Candida albicans response 
by modulating TLR and dectin-1 signals. JImmunol (2012) 189:287-95. doi:10.4049/jimmunol.1103564

38. Sonego F, Castanheira FV, Czaikoski PG, Kanashiro A, Souto FO, Franca RO, et al. MyD88-, but not Nod1- and/or Nod2-deficient mice, show increased susceptibility to polymicrobial sepsis due to impaired local inflammatory response. PLoS One (2014) 9:e103734. doi:10.1371/journal.pone.0103734

39. Dal-Secco D, Freitas A, Abreu MA, Garlet TP, Rossi MA, Ferreira SH, et al. Reduction of ICAM-1 expression by carbon monoxide via soluble guanylate cyclase activation accounts for modulation of neutrophil migration. Naunyn Schmiedebergs Arch Pharmacol (2010) 381:483-93. doi:10.1007/ s00210-010-0500-2

40. Cunha FQ, Assreuy J, Moss DW, Rees D, Leal LM, Moncada S, et al. Differential induction of nitric oxide synthase in various organs of the mouse during endotoxaemia: role of TNF-alpha and IL-1-beta. Immunology (1994) 81:211-5.

41. Sakai K, Suzuki H, Oda H, Akaike T, Azuma Y, Murakami T, et al. Phosphoinositide 3-kinase in nitric oxide synthesis in macrophage: critical dimerization of inducible nitric-oxide synthase. J Biol Chem (2006) 281:17736-42. doi:10.1074/jbc.M601896200

42. Szabo C. Hydrogen sulphide and its therapeutic potential. Nat Rev Drug Discov (2007) 6:917-35. doi:10.1038/nrd2425

43. Spiller F, Orrico MI, Nascimento DC, Czaikoski PG, Souto FO, Alves-Filho JC, et al. Hydrogen sulfide improves neutrophil migration and survival in sepsis via K+ATP channel activation. Am J Respir Crit Care Med (2010) 182:360-8. doi:10.1164/rccm.200907-1145OC

44. Mestriner FL, Spiller F, Laure HJ, Souto FO, Tavares-Murta BM, Rosa JC, et al. Acute-phase protein alpha-1-acid glycoprotein mediates neutrophil migration failure in sepsis by a nitric oxide-dependent mechanism. Proc Natl Acad Sci U S A (2007) 104:19595-600. doi:10.1073/pnas.0709681104

45. Torres-Duenas D, Celes MR, Freitas A, Alves-Filho JC, Spiller F, Dal-Secco D, et al. Peroxynitrite mediates the failure of neutrophil migration in severe polymicrobial sepsis in mice. Br J Pharmacol (2007) 152:341-52. doi:10.1038/ sj.bjp.0707393

46. Wu Z, Sawamura T, Kurdowska AK, Ji HL, Idell S, Fu J. LOX-1 deletion improves neutrophil responses, enhances bacterial clearance, and reduces lung injury in a murine polymicrobial sepsis model. Infect Immun (2011) 79:2865-70. doi:10.1128/IAI.01317-10

47. Freitas A, Alves-Filho JC, Victoni T, Secher T, Lemos HP, Sonego F, et al. IL-17 receptor signaling is required to control polymicrobial sepsis. J Immunol (2009) 182:7846-54. doi:10.4049/jimmunol.0803039

48. Reddy RC, Narala VR, Keshamouni VG, Milam JE, Newstead MW, Standiford TJ. Sepsis-induced inhibition of neutrophil chemotaxis is mediated by activation of peroxisome proliferator-activated receptor-\{gamma\}. Blood (2008) 112:4250-8. doi:10.1182/blood-2007-12-128967

49. Ferreira AE, Sisti F, Sonego F, Wang S, Filgueiras LR, Brandt S, et al. PPAR-gamma/IL-10 axis inhibits MyD88 expression and ameliorates murine polymicrobial sepsis. J Immunol (2014) 192:2357-65. doi:10.4049/ jimmunol.1302375

50. Alves-Filho JC, Spiller F, Cunha FQ. Neutrophil paralysis in sepsis. Shock (2010) 34(Suppl 1):15-21. doi:10.1097/SHK.0b013e3181e7e61b

51. Kovach MA, Standiford TJ. The function of neutrophils in sepsis. Curr Opin Infect Dis (2012) 25:321-7. doi:10.1097/QCO.0b013e3283528c9b

52. Hoesel LM, Neff TA, Neff SB, Younger JG, Olle EW, Gao H, et al. Harmful and protective roles of neutrophils in sepsis. Shock (2005) 24:40-7. doi:10.1097/01. shk.0000170353.80318.d5

53. Brown KA, Brain SD, Pearson JD, Edgeworth JD, Lewis SM, Treacher DF. Neutrophils in development of multiple organ failure in sepsis. Lancet (2006) 368:157-69. doi:10.1016/s0140-6736(06)69005-3

54. Zhang S, Rahman M, Qi Z, Thorlacius H. Simvastatin antagonizes CD40L secretion, CXC chemokine formation, and pulmonary infiltration of neutrophils in abdominal sepsis. J Leukoc Biol (2011) 89:735-42. doi:10.1189/ jlb.0510279

55. Hwaiz R, Rahman M, Syk I, Zhang E, Thorlacius H. Rac1-dependent secretion of platelet-derived CCL5 regulates neutrophil recruitment via activation of alveolar macrophages in septic lung injury. J Leukoc Biol (2015) 97:975-84. doi:10.1189/jlb.4A1214-603R

56. Johnston B, Burns AR, Suematsu M, Issekutz TB, Woodman RC, Kubes P. Chronic inflammation upregulates chemokine receptors and induces neutrophil migration to monocyte chemoattractant protein-1. J Clin Invest (1999) 103:1269-76. doi:10.1172/JCI5208
57. Speyer CL, Gao H, Rancilio NJ, Neff TA, Huffnagle GB, Sarma JV, et al. Novel chemokine responsiveness and mobilization of neutrophils during sepsis. Am J Pathol (2004) 165:2187-96. doi:10.1016/S0002-9440(10)63268-3

58. Hartl D, Krauss-Etschmann S, Koller B, Hordijk PL, Kuijpers TW, Hoffmann F, et al. Infiltrated neutrophils acquire novel chemokine receptor expression and chemokine responsiveness in chronic inflammatory lung diseases. J Immunol (2008) 181:8053-67. doi:10.4049/jimmunol.181.11.8053

59. Souto FO, Alves-Filho JC, Turato WM, Auxiliadora-Martins M, Basile - Filho A, Cunha FQ. Essential role of CCR2 in neutrophil tissue infiltration and multiple organ dysfunction in sepsis. Am J Respir Crit Care Med (2011) 183:234-42. doi:10.1164/rccm.201003-0416OC

60. Talbot J, Bianchini FJ, Nascimento DC, Oliveira RD, Souto FO, Pinto LG, et al. CCR2 expression in neutrophils plays a critical role in their migration into the joints in rheumatoid arthritis. Arthritis Rheumatol (2015) 67:1751-9. doi:10.1002/art.39117

61. Brinkmann V, Reichard U, Goosmann C, Fauler B, Uhlemann Y, Weiss DS, et al. Neutrophil extracellular traps kill bacteria. Science (2004) 303:1532-5. doi:10.1126/science. 1092385

62. Luo L, Zhang S, Wang Y, Rahman M, Syk I, Zhang E, et al. Proinflammatory role of neutrophil extracellular traps in abdominal sepsis. Am J Physiol Lung Cell Mol Physiol (2014) 307:L586-96. doi:10.1152/ajplung.00365.2013

63. Martinod K, Fuchs TA, Zitomersky NL, Wong SL, Demers M, Gallant M, et al. PAD4-deficiency does not affect bacteremia in polymicrobial sepsis and ameliorates endotoxemic shock. Blood (2015) 125:1948-56. doi:10.1182/ blood-2014-07-587709

64. McDonald B, Urrutia R, Yipp BG, Jenne CN, Kubes P. Intravascular neutrophil extracellular traps capture bacteria from the bloodstream during sepsis. Cell Host Microbe (2012) 12:324-33. doi:10.1016/j.chom.2012.06.011

65. Czaikoski PG, Mota JM, Nascimento DC, Sonego F, Castanheira FV, Melo PH, et al. Neutrophil extracellular traps induce organ damage during experimental and clinical sepsis. PLoS One (2016) 11:e0148142. doi:10.1371/journal. pone. 0148142

66. Liu FC, Chuang YH, Tsai YF, Yu HP. Role of neutrophil extracellular traps following injury. Shock (2014) 41:491-8. doi:10.1097/shk. 0000000000000146

67. Gupta AK, Joshi MB, Philippova M, Erne P, Hasler P, Hahn S, et al. Activated endothelial cells induce neutrophil extracellular traps and are susceptible to NETosis-mediated cell death. FEBS Lett (2010) 584:3193-7. doi:10.1016/j. febslet.2010.06.006

68. Gao X, Hao S, Yan H, Ding W, Li K, Li J. Neutrophil extracellular traps contribute to the intestine damage in endotoxemic rats. J Surg Res (2015) 195:211-8. doi:10.1016/j.jss.2014.12.019

69. Tanaka K, Koike Y, Shimura T, Okigami M, Ide S, Toiyama Y, et al. In vivo characterization of neutrophil extracellular traps in various organs of a murine sepsis model. PLoS One (2014) 9:e111888. doi:10.1371/journal. pone. 0111888

70. Clark SR, Ma AC, Tavener SA, McDonald B, Goodarzi Z, Kelly MM, et al. Platelet TLR4 activates neutrophil extracellular traps to ensnare bacteria in septic blood. Nat Med (2007) 13:463-9. doi:10.1038/nm1565

71. Scheibner KA, Lutz MA, Boodoo S, Fenton MJ, Powell JD, Horton MR. Hyaluronan fragments act as an endogenous danger signal by engaging TLR2. J Immunol (2006) 177:1272-81. doi:10.4049/jimmunol.177.2.1272

72. Xu J, Zhang X, Pelayo R, Monestier M, Ammollo CT, Semeraro F, et al. Extracellular histones are major mediators of death in sepsis. Nat Med (2009) 15:1318-21. doi:10.1038/nm.2053

73. Allam R, Scherbaum CR, Darisipudi MN, Mulay SR, Hagele H, Lichtnekert J, et al. Histones from dying renal cells aggravate kidney injury via TLR2 and TLR4. JAm Soc Nephrol (2012) 23:1375-88. doi:10.1681/ asn. 2011111077

74. Saffarzadeh M, Juenemann C, Queisser MA, Lochnit G, Barreto G, Galuska SP, et al. Neutrophil extracellular traps directly induce epithelial and endothelial cell death: a predominant role of histones. PLoS One (2012) 7:e32366. doi:10.1371/journal.pone.0032366

75. Brealey D, Singer M. Multi-organ dysfunction in the critically ill: effects on different organs. JR Coll Physicians Lond (2000) 34:428-31. doi:10.7861/ jroycollphys.34-5-428

76. Windsor AC, Mullen PG, Fowler AA, Sugerman HJ. Role of the neutrophil in adult respiratory distress syndrome. Br J Surg (1993) 80:10-7. doi:10.1002/ bjs. 1800800106 
77. Astiz ME, DeGent GE, Lin RY, Rackow EC. Microvascular function and rheologic changes in hyperdynamic sepsis. Crit Care Med (1995) 23:265-71. doi:10.1097/00003246-199502000-00011

78. Fink MP, Evans TW. Mechanisms of organ dysfunction in critical illness: report from a Round Table Conference held in Brussels. Intensive Care Med (2002) 28:369-75. doi:10.1007/s00134-001-1205-2

79. Aird WC. The role of the endothelium in severe sepsis and multiple organ dysfunction syndrome. Blood (2003) 101:3765-77. doi:10.1182/ blood-2002-06-1887

80. Rees DD, Monkhouse JE, Cambridge D, Moncada S. Nitric oxide and the haemodynamic profile of endotoxin shock in the conscious mouse. Br J Pharmacol (1998) 124:540-6. doi:10.1038/sj.bjp.0701815

81. Kooy NW, Lewis SJ, Royall JA, Ye YZ, Kelly DR, Beckman JS. Extensive tyrosine nitration in human myocardial inflammation: evidence for the presence of peroxynitrite. Crit Care Med (1997) 25:812-9. doi:10.1097/00003246199705000-00017

Conflict of Interest Statement: The authors declare the absence of any commercial or financial relationships that could be construed as a potential conflict of interest.

Copyright (C) 2016 Sônego, Castanheira, Ferreira, Kanashiro, Leite, Nascimento, Colón, Borges, Alves-Filho and Cunha. This is an open-access article distributed under the terms of the Creative Commons Attribution License (CC BY). The use, distribution or reproduction in other forums is permitted, provided the original author(s) or licensor are credited and that the original publication in this journal is cited, in accordance with accepted academic practice. No use, distribution or reproduction is permitted which does not comply with these terms. 